\title{
Saccade and Cognitive Function in Chronic Kava Users
}

\author{
Sheree Cairney*, I,2,3, Alan R Clough ${ }^{3}$, Paul Maruff ${ }^{1,2}$, Alex Collie', Bart J Currie ${ }^{3}$ and Jon Currie ${ }^{1,4}$ \\ 'The Neurophysiology and Neurovisual Research Unit, Mental Health Research Institute of Victoria, Parkville, Victoria, Australia; ${ }^{2}$ School of \\ Psychological Science, La Trobe University, Bundoora, Victoria, Australia; ${ }^{3}$ Menzies School of Health Research and Northern Territory Clinical \\ School, Royal Darwin Hospital, Casuarina, Australia; ${ }^{4}$ Brain Research Unit, Drug and Alcohol Services, Westmead Hospital, Westmead, Sydney, \\ Australia
}

\begin{abstract}
Kava is an extract from the Piper methysticum Forst. f. plant that has been consumed in the Pacific islands for millennia and more recently, among indigenous populations, in northern Australia and throughout the Western world as an herbal medicine. Through alterations on neuronal excitation, kava induces muscle relaxation, anasthesia, and has anxiolytic properties. There have been several isolated reports of psychotic syndromes, severe choreoathetosis and possible seizures following kava use. However, there is no conclusive evidence that kava interferes with normal cognitive processes. We tested a group of current, ex, and nonkava users among an indigenous population in northern Australia, using saccade and cognitive tests that have proven cross-cultural validity and are sensitive to subtle disruptions of the brain arising from substance abuse or neuropsychiatric illness. Despite collecting data from among the heaviest reported kava drinkers in the world, we found no impairment in cognitive or saccade function in individuals who were currently heavy kava users (and had been for up to 18 years), nor was there any impairment in individuals who had been heavy kava users in the past but had abstained for longer than 6 months. Current and ex-kava users showed a higher rate of kava dermopathy, lower body mass index, lowered blood lymphocytes and, in addition, current kava users showed elevated liver enzymes. While there has recently been increasing concern about potentially fatal liver damage attributed to kava use, we have found no evidence of brain dysfunction in heavy and long-term kava users. Neuropsychopharmacology (2003) 28, 389-396. doi: I 0. I038/sj.npp. 1300052
\end{abstract}

Keywords: $\quad$ Piper methysticum; kava; chronic; cognitive; saccade; choreoathetosis

\section{INTRODUCTION}

Kava is an intoxicating beverage made from the root extract of the Piper methysticum Forst. f. plant that is native to the Pacific Islands, and where it has been used in ceremonial settings for millennia (Singh, 1992). The root is ground, added to water, and usually drunk from a communal bowl (Lebot et al, 1997). The main psychopharmacological actions of kava arise from a lipid soluble group of compounds known as kava lactones. These give rise to the reinforcing effects of kava that include muscle relaxation, sedation, analgesia, and intoxication, which resolve completely once acute toxicity ceases and kava metabolites are cleared from the body (Cawte, 1986; Singh, 1992; Lebot et al, 1997). Recently, the recreational use of kava has increased among indigenous populations in northern Australia, amid growing concern about its adverse health effects (Mathews et al, 1988). For example, there are reports of increased risk of serious infection, liver abnormalities, loss of body fat and dermopathy in heavy kava users (Mathews et al, 1988; Currie, 2000). In addition to ceremonial and recreational use, kava-based products are now marketed as natural

\footnotetext{
*Correspondence: Dr S Cairney, Menzies School of Health Research, Northern Territory Clinical School, Royal Darwin Hospital, PO Box 41096, Casuarina NT 081।, Australia, Tel: +61 88922 8196, Fax: +61 88927 5।87, E-mail: scairney@mhri.edu.au

Received 17 April 2002; revised 2 August 2002; accepted 20 August 2002
}

therapies for the treatment of anxiety and tension (Wong et $a l, 1998)$. These products have recently been withdrawn from distribution in several European countries as they are linked with increasing reports of liver failure, including one fatality (Escher et al, 2001; Russmann et al, 2001; Blumenthal, 2002). Studies of these kava-based products have contributed to our understanding of kava's action on the brain.

Studies of single neurons indicate that kava lactones act directly to alter voltage-dependent ion channels and thereby disrupt GABAergic, serotonergic, and dopaminergic neurotransmission and this occurs predominantly in the hippocampus and amygdala complex (Cairney et al, 2002). Despite this evidence, the effect that acute and chronic kava exposure has on human cognitive processes remains unclear. Several studies report no change in cognitive function immediately following kava ingestion (Prescott $e t$ al, 1993; Russell et al, 1987; Foo and Lemon, 1997) while others report subtle disruption to attentional and memory processes (Münte et al, 1993; Heinze et al, 1994). This debate is complicated further by the finding that small doses of kava can improve attentional function while larger doses cause sedation, which then gives rise to impairment in the same attentional functions (Saletu et al, 1989).

Only two studies investigated the cognitive effects of longterm kava exposure. Healthy humans given $600 \mathrm{mg} /$ day kava lactones for 5 days showed nonsignificant increases in 
the frequency of correct responses on a word-recognition task (Münte et al, 1993). The second study found no abnormalities on tests of picture recognition, card sorting, maze tracing, line tracing, memory, and coordination in a group of indigenous Australians, who had regularly used up to $440 \mathrm{~g} /$ week of kava powder for a maximum of 6 years (Mathews et al, 1988). However, this may reflect that the tests used were inappropriate for tribal indigenous groups or were not sufficiently sensitive to the effects of kava. A recent study found that cognitive impairment caused by the prolonged use of cannabis, recognized as a more potent psychomimetic than kava, is only detected following 10-20 years of near daily use (Solowij et al, 2002). Therefore, it is also possible that, although Mathews et al (1988) found no cognitive deficits following up to 6 years of heavy kava use, cognitive changes may be observed among a group with a more prolonged history of heavy kava use.

There is increasing evidence that kava use is associated with some brain impairment. For example, there have been several case reports of severe choreoathetosis following kava use (Schelosky et al, 1995; Spillane et al, 1997) and we have recently raised the possibility of an association between heavy kava use and seizures, either from toxicity or on withdrawal (Clough et al, 2001). In addition, the use of kava has been associated with hallucinations (Brunton, 1988) and an improvement in psychotic symptoms among psychiatric patients (Cawte, 1986). A further issue is that although the acute effects of kava resolve as soon as the drug is cleared and no longer being ingested, it is not known whether there are chronic effects and whether these resolve with abstinence.

To assess the neurobehavioral function in tribal indigenous people, it is necessary to select tests with demonstrated appropriateness and acceptability among individuals with no exposure to psychological or educational testing and who do not speak English as the primary language. We have developed a battery of saccadic and cognitive tests that have been shown to meet these requirements, as they involve responding with a hand or eye movement to visual nonmeaningful stimuli and require no language and minimal, if any, instruction. Since saccades can be recorded with much greater precision than many other physiological functions, the ocular motor system is commonly examined in the evaluation of brain function. Behavioral parameters such as saccadic latency, saccadic peak velocity, saccadic accuracy, and the behavioral control of saccades (ie antisaccade task) have proven sensitive to the effects of both prescription and illicit drugs (Leigh and Zee, 1999). Furthermore, the anatomical substrates and physiological organization underlying these parameters are well known at both cortical and subcortical levels. The cognitive tests were drawn from the computerized Cambridge Automated Neuropsychological Test Battery (CANTAB) that has been designed to provide easy and rapid administration and scoring with minimal reliance on verbal (English language) skills, while examining the major cognitive domains. From this CANTAB battery, we include tests of basic motor function (motor screening), visual recognition memory (pattern recognition), visual attention (visual search) and visuo-spatial learning/memory (pattern-location paired associate learning). Owing to their simplicity, these saccade and cognitive tests have been consistently validated in healthy and brain-impaired adults and children, and have consequently proven sensitive to a wide spectrum of performance levels, subtle disruptions of attentional and memory systems, and to the effects of both sedating and stimulant drugs (Tedeschi et al, 1983a, b; Hotson et al, 1986; Sahakian et al, 1988; Currie et al, 1992, 1993; Owen et al, 1993, 1995; Maruff et al, 1996, 1998; Elliot et al, 1997; Robbins et al, 1997; Cairney et al, 2001). Since these tests have been used in neuroimaging studies and during singlecell recordings in primates, performance measures can be interpreted within robust brain-behavior models. To investigate the consequences of chronic kava use on neurobehavioral function, we therefore used this battery of tests to assess indigenous Australians who had been heavy kava drinkers for up to 18 years, some of whom had since abstained, and controls that had never consumed kava.

The severity of kava use was rated according to an established consensual methodology that rates the severity of substance abuse in remote rural indigenous populations (Mathews et al, 1988; Burns et al, 1995; Maruff et al, 1998; Clough et al, 2002) and, in addition, we assessed biochemical and physical parameters that have previously proven to be markers of heavy kava use (Mathews et al, 1988). These include measures of body fat, skin dermopathy, and serological measures of blood lymphocytes and the liver enzymes - glutamyl transferase (GGT) and alkaline phosphatase (ALP). Finally, in the study region, djadaw' marama is a term in the local Gumatj dialect that is used to describe the heaviest kava users, who are known to drink kava for 24 hours (and more) in continuous drinking sessions. To assess the impact on brain function of this recognized pattern of heavy usage, a subgroup of kava users were subclassified as djadaw'marama according to local informants. Neurobehavioral performance in this subgroup was then compared separately with a control group.

\section{METHODS}

\section{Participants}

A total of 101 individuals (65 males, 36 females) aged between 17 and 66 years participated in the study. Participants were classified into groups according to consensual ratings from the participant and local community health workers, who resided in the same communities (Mathews et al, 1988; Burns et al, 1995; Maruff et al, 1998). We have described this consensual rating methodology in detail previously (Burns et al, 1995; Maruff et al, 1998; Clough et al, 2002). Participants were classified into one of the three groups. Current kava users were individuals who were currently and actively using kava and had done so for more than 6 months. Ex-kava users were individuals who had used kava previously for a period of at least 6 months but who, at the time of the study, had not used kava for at least 6 months. Nonkava users had never used kava. The patterns of kava use in these groups are shown in Table 1. Individuals were excluded from the study if they had a history of seizures, head injury with loss of consciousness, or psychiatric illness. The use of petrol, alcohol, and cannabis was also common among the sample population. Participants currently abusing any of these substances were excluded from the data set to ensure that chronic use of 
Table I Demographic, Biochemical, Physical, and Behavioral Variables in the Non, Ex, and Current Kava Groups

\begin{tabular}{|c|c|c|c|c|c|c|c|c|}
\hline & $\begin{array}{l}\text { Nonkava } \\
(n=26)\end{array}$ & & $\begin{array}{l}\text { Ex-kava } \\
(n=14)\end{array}$ & & $\begin{array}{l}\text { Current kava } \\
(n=18)\end{array}$ & Statistic & $p$-value & $\eta^{2}$ \\
\hline \multicolumn{9}{|l|}{ Demographic } \\
\hline Age (years) & $34.8 \pm 10.4$ & $=$ & $38.8 \pm 13.0$ & $=$ & $33.7 \pm 7.2$ & $F=0.98$ & NS & 0.03 \\
\hline Age range & $(17-54)$ & & $(19-62)$ & & $(25-46)$ & & & \\
\hline Males, females & 12,14 & & 8,6 & & 16,2 & & & \\
\hline \multicolumn{9}{|l|}{ Biochemical $^{a}$ (percentage abnormal) } \\
\hline Lymphocytes (reduced) & $15.4 \%$ & $<$ & $35.7 \%$ & $=$ & $44.4 \%$ & $\chi^{2}=19.37$ & $<0.001$ & \\
\hline GGT (elevated) & $30.8 \%$ & $=$ & $28.6 \%$ & $<$ & $50.0 \%$ & $\chi^{2}=7.75$ & 0.005 & \\
\hline ALP (elevated) & $19.2 \%$ & $=$ & $21.4 \%$ & $<$ & $44.4 \%$ & $\tilde{\chi}^{2}=15.45$ & $<0.00$ । & \\
\hline \multicolumn{9}{|l|}{ Physical } \\
\hline $\mathrm{BMI}^{\mathrm{a}}$ & $22.7 \pm 4.6$ & $=>$ & $20.9 \pm 3.4$ & $=>$ & $19.0 \pm 2.2$ & $F=3.74$ & 0.035 & 0.19 \\
\hline Presence of kava dermopathy & $0 \%$ & & $14.3 \%$ & & $44.4 \%$ & $\chi^{2}=9.67$ & $<0.001$ & \\
\hline \multicolumn{9}{|l|}{ Behavioral } \\
\hline No. of ex-petrol sniffers & 7 & & । & & 5 & $\chi^{2}=0.003$ & NS & \\
\hline No. of alcohol users & 4 & & 6 & & 15 & $\bar{\chi}^{2}=7.61$ & 0.006 & \\
\hline Age when started drinking alcohol & $22.3 \pm 7.5$ & $=$ & $19.8 \pm 6.4$ & $=$ & $18.4 \pm 4.5$ & $\mathrm{~F}=0.8 \mathrm{I}$ & NS & 0.07 \\
\hline No. of years drinking alcohol & $15.5 \pm 13.2$ & $=$ & $14.5 \pm 11.0$ & $=$ & $15.5 \pm 8.6$ & $F=0.02$ & NS & 0.002 \\
\hline No. of cannabis users & 3 & & 5 & & 8 & $\chi^{2}=3.38$ & NS & \\
\hline Age when started smoking cannabis & $17.7 \pm 2.3$ & $=$ & $22.2 \pm 6.1$ & $=$ & $26.6 \pm 8.0$ & $\tilde{F}=2.01$ & NS & 0.24 \\
\hline No. of years smoking cannabis & $2.7 \pm 1.2$ & $=$ & $5.8 \pm 4.8$ & $=$ & $6.0 \pm 6.3$ & $F=0.45$ & NS & 0.07 \\
\hline Average of cones/week & $2.8 \pm 0.5$ & $=$ & $5.2 \pm 4.2$ & $=$ & $4.7 \pm 5.1$ & $F=0.59$ & NS & 0.08 \\
\hline Age when started drinking kava (years) & & & $25.9 \pm 9.5$ & $=$ & $21.9 \pm 6.5$ & $F=|.9|$ & NS & 0.06 \\
\hline No. of years drinking & & & $13.0 \pm 5.7$ & $=$ & $11.7 \pm 6.2$ & $F=0.36$ & NS & 0.01 \\
\hline Volume of kava (g/week) & & & $262 \pm 172$ & $=$ & $316 \pm 135$ & $F=0.39$ & NS & 0.02 \\
\hline
\end{tabular}

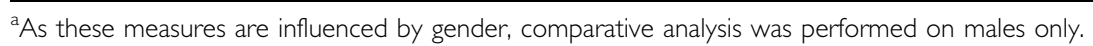

these substances did not confound the outcomes of kava use. Two individuals were excluded on the basis of their recent practice of petrol sniffing. Of the remaining sample group, $22.4 \%$ had sniffed petrol in the past, although this had not occurred for at least 5 years. Moreover, those with a history of petrol sniffing were distributed evenly throughout our 3 groups (see Table 1). No individual met the DSM-IV criteria (American Psychiatric Association, 1994) for abuse or dependence of either alcohol or cannabis. The consumption of alcohol was illegal in the community at the time of testing and although this did not completely eradicate the practice, the drinking of alcohol occurred irregularly. Among alcohol users, the average monthly consumption of approximately $400 \mathrm{ml}$ pure ethanol was considerably less than in the surrounding region where users consume an average of $1500 \mathrm{ml}$ pure ethanol per month (Clough et al, in press). No participant had an average monthly consumption of more than $800 \mathrm{ml}$ of pure ethanol. Cannabis had only been readily available in the community for 4 years at the time of the study (Clough et al, in press). Consequently, the cannabis users within our groups did not have a long history of cannabis use (average 5.3 years). To ensure no heavy cannabis users were included in our analysis, a conservative cutoff was selected and individuals who consumed more than 14 cones per week (from our estimates, approximately $0.9 \mathrm{~g}$ cannabis plant matter, or approximately $36 \mathrm{mg}$ THC; Hall and Swift, 2000) were excluded from the study. One individual was excluded on these criteria. To ensure that no individual was acutely intoxicated with kava, alcohol, or cannabis during testing, those who had used any of these substances in the $24 \mathrm{~h}$ prior to testing were excluded from the study. Using these criteria, 11 individuals were excluded for recent kava use, 11 for recent cannabis use, and 4 for recent alcohol use. The final study sample consisted of 26 nonkava, 14 ex-kava, and 18 current kava users. Among users, the duration of kava use ranged from 1 to 18 years. A memorandum of understanding between the local Aboriginal community Council and the Menzies School of Health Research guided the research. The Institutional Ethics Committee of the Menzies School of Health Research and Royal Darwin Hospital with input from an Aboriginal subcommittee granted ethical approval. All participants gave written informed consent to the studies.

\section{Procedure}

Biochemical. Blood samples were taken from each subject for analysis of blood lymphocytes and the liver enzymes, GGT and ALP.

Physical. Sitting and standing heights were measured with a stadiometer and weight using a Tanita Body Fat ('Tanita' TBF 521(1998), Milners, Perth) device. The body mass index (BMI) was calculated (Wang et al, 2001). Participants were examined by a physician who was blind to their group classification for the presence of kava dermopathy.

Saccade tests. Eye movement (saccade) recordings were performed in a darkened room, using a high-resolution infrared scleral reflectance technique (IRIS, Skalar; bandwidth DC to $100 \mathrm{~Hz}(-3 \mathrm{~dB})$ ), with the head stabilized. Individuals were seated $1 \mathrm{~m}$ from a screen with backprojection of a laser target, computer controlled by $X-Y$ 
mirror galvanometers (General Scanning, MA). Eye and target position signals were digitized at $1 \mathrm{kHz}$ and scored for off-line computer analysis. Eye position was differentiated using a computer-based algorithm to obtain eye velocity. All saccade targets are presented on a horizontal plane. Individuals were required to make visually guided saccades to fixate random targets; moving with unpredictable direction, amplitude $\left( \pm 15^{\circ}\right)$, and timing (range 1.5-2.5 s). The initial saccade for each target was scored only if it was in the correct direction. The initial saccade was scored as hypometric if it attained less than $85 \%$ of the target step, and hypermetric if it attained more than $115 \%$ of the target step. Anticipatory saccades were defined as saccades made prior to, or less than, $70 \mathrm{~ms}$ following the target appearance (Smit and Van Gisbergen, 1989). For each individual, saccade latency was calculated as the duration from the onset of the target to the onset of the saccade, and saccade accuracy was calculated as the displacement of the final eye position with respect to the target position. The duration and peak velocity for visually guided saccades were plotted against saccade amplitude. For the antisaccade task, subjects were asked to fixate a central green light-emitting diode (LED; $16.9 \mathrm{~cd} / \mathrm{m}^{2}$ ) target, which was offset simultaneous with the appearance of a peripheral red target, at either $\pm 10^{\circ}$ or $\pm 15^{\circ}$. The rise time of the LED was $3 \mu$ s. Individuals were instructed to inhibit a reflexive saccade to the peripheral red target, and instead to generate an antisaccade to its mirror location and hold fixation until the green LED reappeared in the center. Displacement and timing (3.0-3.5 s after fixation) of the appearance of the peripheral red target was random. A correct antisaccade response was an initial eye movement away from the midline to the side opposite to that of the peripheral red target. Any initial reflexive eye movement towards the target was scored as incorrect, even if a subsequent correction to the opposite side was made. The latency for the onset of correct antisaccades was recorded and a percentage error rate was calculated. Saccade recordings were examined for the presence of nystagmus and fixation instability.

Cognitive tests. The neuropsychometric test battery was drawn from the touchscreen-based CANTAB. All of these tests have been described in detail previously (Owen et al, 1993, 1995; Maruff et al, 1996, 1998). Briefly, for the motor function task, individuals were required to use their dominant hand to touch the middle of a cross that was presented with random timing and at random locations on the computer screen. In all, 12 trials were administered following 12 practice trials. The accuracy and latency of hand movements to touch the computer screen were recorded. The visual search task began with a central box displayed on the computer screen, surrounded by eight additional boxes. The target, a complex abstract pattern consisting of four different colors, then appeared in the central box and remained visible until the end of the trial. After a $2 \mathrm{~s}$ delay, an array of either two or eight similar abstract patterns, one of which was the initial target, appeared in the surrounding boxes. The target therefore appeared with either one or seven similar distracters. Individuals were required to identify which of the (two or eight) surrounding boxes contained the target pattern as quickly as possible by lifting their dominant hand from the response pad and touching the appropriate box. Response times, movement times, and the number of correct hits were recorded. In the pattern recognition task, 12 abstract target patterns were presented sequentially for $2 \mathrm{~s}$ each in the center of the computer screen. After a $3 \mathrm{~s}$ delay, two patterns were then presented simultaneously on the screen, one from the initial 12 targets and one novel, but similar pattern. Individuals were required to touch the target pattern. In all, 12 pairs of stimuli, each containing a target and a distracter, were shown and the entire procedure was then repeated with a new set of 12 target patterns. The number of patterns recognized correctly was recorded. Finally, in the patternlocation paired associate learning task, eight boxes were presented at locations around the edge of the computer screen that were equidistant from the center. At the beginning of a trial, each box opened for $2 \mathrm{~s}$, in random order, to reveal that it contained either an abstract pattern or was empty. Each box closed after $2 \mathrm{~s}$ so that its contents were no longer visible. Individuals were then instructed to remember which of the boxes contained a pattern and what that pattern was. After all of the boxes had opened and closed, a single pattern was presented at the center of the computer screen, which was identical to one of the patterns that the subject had just been shown. The individual was required to touch the box that contained the identical pattern. Another of the recently shown patterns was then presented in the center of the computer screen, and again the individual was required to touch the box that had contained that pattern. This was repeated until all the pattern-location associations that made up the trial had been remembered correctly. If an error was made, the same set of pattern-location associations was shown to the individual again and the learning procedure was repeated. Individuals were required to learn sets of one, two, three, six, or eight pattern-location associations to complete each test. Individuals were allowed up to 10 repeated trials to learn a single set of pattern-location associations. If the set of pattern-location associations was not learned within 10 trials, the set was stopped. The number of trials and errors for each test was recorded.

\section{Data Analysis}

Demographic, physical, and biochemical indices of kava usage were compared between groups using separate analyses of variance (ANOVA). For each group, the percentage of individuals with measures of biochemistry outside the normal reference range $\left(<1.5 \times 10^{9} / 1\right.$ for blood lymphocytes; >135.0 U/1 for ALP; $>40 \mathrm{U} / 1$ for GGT in females and $>60 \mathrm{U} / \mathrm{l}$ for GGT in males) were calculated and submitted to $\chi^{2}$ analysis to compare groups. Saccade duration-amplitude relation were quantified by calculating the linear regression gradient for each individual. The velocity-amplitude relation, known as the main sequence, is typically represented more accurately by a power function for short-amplitude saccades such as those seen in this study, and represented more accurately by an exponential function when large-amplitude saccades are included and velocity saturation occurs (Becker, 1989; Leigh and Zee, 1999). The scatter of points representing the velocityamplitude relation were expressed for each individual as a least-squares curve fit to both a power and an exponential 
function. Using the function that most accurately represented the data across all individuals, two constants were derived for each individual and used as the dependent variables that represented saccade peak velocity for analysis between the groups (Baloh et al, 1975). All saccadic and cognitive measures were compared between groups using ANOVA and significant group differences were investigated using Newman-Keuls post hoc t-tests adjusted for multiple comparisons. For the visual search task, where there were two levels of difficulty (ie either two or eight items), each level was treated as a repeated variable in the ANOVA. Before analysis, the distributions of data for each performance measure were inspected for normality and heterogeneity of variance. Where the data did not meet the assumptions for ANOVA, the distributions of scores were transformed. Logarithmic base 10 (log) transformation was used to transform distributions of raw data that were skewed significantly in the positive direction to normal. This was necessary for CANTAB latency data. Accuracy measures on the CANTAB tasks that were scored as percentage correct, formed negatively skewed distributions and arcsine transformations were used to normalize these distributions. Similar transformations have been used in previous studies using CANTAB measures (Owen et al, 1993, 1995; Maruff et al, 1996, 1998). Where variables did not meet the assumptions for ANOVA after transformation or where data was categorical, scores were submitted to Kruskal-Wallis nonparametric ANOVA to compare groups. The relation between indices of the severity of kava use (demographic, physical, and biochemical) and performance on saccadic and cognitive tests were investigated using Pearson's product moment correlation or Spearman's correlation. The level of significance for comparisons within each of the domains assessed (demographic, physical, biochemical, saccade, and cognitive) was set at 0.05 .

\section{Results}

Demographic, physical, and biochemical characteristics. A greater proportion of males were in the currentkava group than the non- and ex-kava groups. However, there was no difference between the groups for age (see Table 1) and no difference between the ex- and current kava groups for the age at which kava drinking began, the number of years of using kava or the volume of kava ingested each week. The proportion of cannabis users and ex-petrol sniffers were equivalent between the groups, and there were a greater proportion of alcohol users among the current kava group than the nonkava group. However, these were irregular and not heavy alcohol users and this group difference should therefore have no effect on cognitive performance. A greater proportion of individuals had abnormally low blood lymphocytes in both the current and ex-kava groups when compared to the nonkava group. There was also a significant increase in the proportion of individuals from the current kava group with abnormally elevated concentrations of the liver enzymes, GGT and ALP, when compared to the ex- and nonkava groups. The BMI was significantly reduced for both the ex- and current kava group when compared to the nonkava group. Kava dermopathy was observed in $44.4 \%$ of the current kava group, $14.3 \%$ of the ex-kava group, and was not observed in any individual from the nonkava group.

Saccade tests. No participant showed any evidence of nystagmus or significant fixation instability. Group means, standard deviations, and statistical parameters for each of the saccade and cognitive measures are shown in Table 2. For visually guided saccades, the relation between saccade peak velocity and saccade amplitude was described using an exponential curve $\left(r^{2}=0.72\right)$ and a power curve, which provided a better fit $\left(r^{2}=0.80\right)$ and was therefore selected as the most accurate representation of saccade velocity (ie Becker, 1989). No measure of saccade performance was different between the groups.

Cognitive tests. No measure of cognitive performance was different between the groups.

Relation between the severity of kava use and saccadic and cognitive measures. To investigate the variation in saccadic and cognitive performance measures with indicators of the severity of kava use, correlation analysis was performed for the ex- and current kava groups separately. A correlation between the age at which kava use began and the latency of visually guided saccades among current users disappeared when controlled for age. The volume of kava used each week (g/week) and the starting age and duration of use for kava, alcohol, or cannabis did not correlate with any measure of saccadic or cognitive performance among the current or ex-kava groups.

Performance comparisons between heavy kava users (djadaw'marama) and nonkava users. Of the current kava group, 13 individuals were identified as djadaw'marama. On average, these individuals consumed 323 $(\mathrm{SD}=142) \mathrm{g}$ of kava powder each week. Independent samples $t$-tests were used to compare saccadic and cognitive measures between these individuals and a group $(n=13)$ of age and sex-matched controls that had never drank kava. No differences on any of the saccade or cognitive measures were found between these groups (Table 3).

\section{DISCUSSION}

The results of this study suggest strongly that there is no impairment in cognitive or saccadic function in individuals who are heavy and long-term kava users, nor is there any impairment in individuals who have used kava heavily in the past but abstained for longer than 6 months. Three aspects of the study design reassure us that this inference is correct and not because of an incorrect statistical decision (ie Type II error or false negative decision). First, the effect sizes for each comparison were very small indicating that, even if group differences were statistically significant, they were not clinically significant and therefore not meaningful. Second, we have also found the same test battery to be sensitive to the effects of petrol abuse (Maruff et al, 1998), psychiatric illness (Purcell et al, 1998; Pantelis et al, 1997; Cairney et al, 2001) and very early neurodegenerative disease (Currie et al, 1992, 1993; Collie et al, 2001) and many other studies have shown that both licit and illicit drugs alter performance on the saccadic (Tedeschi et al, 
Table 2 Saccade and Cognitive Performance Measures in Non, Ex, and Current kava groups

\begin{tabular}{|c|c|c|c|c|c|c|c|c|}
\hline & $\begin{array}{l}\text { Nonkava } \\
(n=26)\end{array}$ & & $\begin{array}{l}\text { Ex-kava } \\
(n=14)\end{array}$ & & $\begin{array}{l}\text { Current kava } \\
(n=18)\end{array}$ & Statistic & $p$-value & $\eta^{2}$ \\
\hline \multicolumn{9}{|l|}{ Saccade measures } \\
\hline \multicolumn{9}{|l|}{ Visually guided saccades } \\
\hline Hypometric (range) & $12.5 \%(0-37)$ & $=$ & $10.1 \%(0-24)$ & $=$ & $7.4 \%(0-25)$ & $\chi^{2}=7.1^{\mathrm{a}}$ & NS & \\
\hline Hypermetric (range) & $6.2 \%(0-23)$ & $=$ & $4.9 \%(0-12)$ & $=$ & $6.2 \%(0-24)$ & $\chi^{2}=0.3^{a}$ & NS & \\
\hline Anticipations (range) & $15.2 \%(0-36)$ & $=$ & $17.6 \%(0-45)$ & $=$ & $10.8 \%(0-23)$ & $\chi^{2}=2.4^{a}$ & NS & \\
\hline Latency (ms) & $182.4 \pm 24.7$ & $=$ & $187.7 \pm 32.0$ & $=$ & $181.7 \pm 29.9$ & $\mathrm{~F}=0.20$ & NS & 0.007 \\
\hline Accuracy (\%) & $98.4 \pm 3.7$ & $=$ & $99.6 \pm 2.9$ & $=$ & $100.2 \pm 4.9$ & $F=1.17$ & NS & 0.04 \\
\hline Peak velocity (coefficient) & $143.0 \pm 34.5$ & $=$ & $159.5 \pm 29.4$ & $=$ & $161.3 \pm 33.5$ & $F=1.99$ & NS & 0.07 \\
\hline Duration (amplitude gradient) & $2.2 \pm 0.9$ & $=$ & $2.2 \pm 0.4$ & $=$ & $2.0 \pm 0.4$ & $F=0.63$ & NS & 0.02 \\
\hline \multicolumn{9}{|l|}{ Antisaccades } \\
\hline Latency (ms) & $322.1 \pm 95.5$ & $=$ & $286.2 \pm 79.4$ & $=$ & $356.8 \pm 230.5$ & $F=0.43$ & NS & 0.03 \\
\hline Error rate (\%) & $29.1 \pm 22.2$ & $=$ & $27.1 \pm 19.4$ & $=$ & $27.8 \pm 22.4$ & $F=0.04$ & NS & 0.002 \\
\hline \multicolumn{9}{|l|}{ Cognitive Measures } \\
\hline Motor screening (log latency) & $2.93 \pm 0.11$ & $=$ & $2.96 \pm 0.13$ & $=$ & $2.89 \pm 0.11$ & $F=1.55$ & NS & 0.05 \\
\hline \multicolumn{9}{|l|}{ Pattern recognition } \\
\hline (log correct latency) & $3.49 \pm 0.18$ & $=$ & $3.63 \pm 0.25$ & $=$ & $3.59 \pm 0.22$ & $F=2.48$ & NS & 0.08 \\
\hline (arcsine percentage correct) & $0.84 \pm 0.27$ & $=$ & $0.78 \pm 0.23$ & $=$ & $0.81 \pm 0.20$ & $F=0.31$ & NS & 0.01 \\
\hline \multicolumn{9}{|l|}{ Visual search } \\
\hline Two pairs (arcsine \% correct) & $1.55 \pm 0.08$ & $=$ & $1.57 \pm 0.0$ & $=$ & $1.5 \mid \pm 0.16$ & $F=1.21$ & & \\
\hline Eight pairs (arcsine \% correct) & $1.18 \pm 0.31$ & $=$ & $1.16 \pm 0.34$ & $=$ & $1.43 \pm 0.28$ & $F=3.62$ & NS & 0.37 \\
\hline \multicolumn{9}{|c|}{ Pattern-location paired associative learning } \\
\hline Total errors & $29.2 \pm 16.0$ & $=$ & $29.9 \pm 14.3$ & $=$ & $27.4 \pm 15.8$ & $F=0.11$ & NS & 0.004 \\
\hline List memory & $15.0 \pm 4.5$ & $=$ & $13.0 \pm 2.7$ & $=$ & $14.8 \pm 3.8$ & $F=1.27$ & NS & 0.04 \\
\hline
\end{tabular}

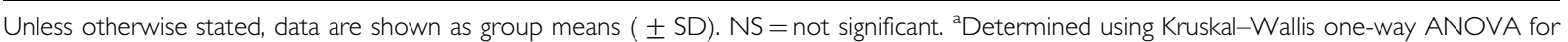
nonparametric statistics.

Table 3 Saccade and Cognitive Measures in Nonkava users and Heavy kava Users (djadaw'marama)

\begin{tabular}{|c|c|c|c|c|}
\hline Measure & $\begin{array}{l}\text { Nonkava users } \\
(n=13)\end{array}$ & $\begin{array}{l}\text { Heavy kava users } \\
\text { (djadaw'marama) } \\
(n=13)\end{array}$ & $t$-value & $p$-value \\
\hline Age & $34.1+11.8$ & $32.6+7.8$ & -0.37 & NS \\
\hline Duration of kava use (years) & $0^{-}$ & $12.5 \pm 1.5$ & & \\
\hline Volume of kava (g/week) & 0 & $323 \pm 142$ & & \\
\hline Saccade latency (ms) & $184.9 \pm 31.2$ & $184.0 \pm 34.2$ & -0.08 & NS \\
\hline Saccade accuracy (\% of target acquisition) & $98.8 \pm 4.1$ & $100.6 \pm 5.6$ & 0.92 & NS \\
\hline Saccade peak velocity (coefficient) & $142.4 \pm 21.9$ & $157.4 \pm 31.3$ & 1.41 & NS \\
\hline Saccade duration (amplitude gradient) & $2.4 \pm 1.2$ & $2.1 \pm 0.5$ & -0.82 & NS \\
\hline Antisaccade latency (ms) & $336.3 \pm 115.2$ & $366.6 \pm 266.9$ & 0.38 & NS \\
\hline Antisaccade error rate (\%) & $30.1 \pm 27.0$ & $28.6 \pm 25.8$ & -0.14 & NS \\
\hline \multicolumn{5}{|l|}{ Pattern recognition } \\
\hline (arcsine \% correct) & $0.92 \pm 0.3$ & $0.74 \pm 0.2$ & -1.75 & NS \\
\hline $\begin{array}{l}\text { Visual search from eight stimuli } \\
\text { (arcsine \% correct) }\end{array}$ & $1.2 \pm 0.3$ & $1.4 \pm 0.3$ & 1.64 & NS \\
\hline \multicolumn{5}{|l|}{ Paired associate learning } \\
\hline List memory & $14.0 \pm 4.0$ & $14.5 \pm 3.9$ & 0.35 & NS \\
\hline Total errors & $32.5 \pm 16.4$ & $29.5 \pm 14.7$ & -0.48 & NS \\
\hline
\end{tabular}

1983a, b; Hotson et al, 1986) and the cognitive function tests (Sahakian et al, 1993; Elliot et al, 1997; Robbins et al, 1997) used here. Third, we are confident that individuals in this study were heavy kava users. The consensual methodology for the classification of substance use has been used extensively in indigenous communities (Mathews et al, 1988; Burns et al, 1995; Maruff et al, 1998; Clough et al, 2002). We took extensive histories of kava use from individuals, their health clinic records, and from informants in the same communities. In addition, changes to the legal status of kava in the region, several years prior to the study, caused a reduction in consumption levels, and our participants are likely to have consumed greater volumes of kava in the past than those reported here (Clough et al, in press). We were also careful to exclude individuals with other psychiatric and neurological disorders or individuals who abuse other substances that may affect cognitive function. Evidence of appropriate classification was in the higher rate of kava dermopathy, decreased blood lymphocytes, and lower BMI observed in both the current and exkava user groups, and the elevated GGT in the current kava group. These same observations were reported previously in 
heavy kava users (Mathews et al, 1988). For these reasons, we also believe that the control group used in the current study did not consist of individuals who used kava regularly, but who had not reported such use. Furthermore, the levels of cognitive and saccadic performance seen here were similar for groups of indigenous Australians who have served as control groups in our previous studies (Maruff et al, 1996, 1998). Therefore, the observation of normal cognitive, and saccadic function, in the individuals studied here, suggests strongly that the long-term and heavy use of kava is not associated with any progressive deterioration of brain function, even in individuals who have regularly used excessive amounts of kava for up to 18 years. These results are therefore consistent with those of an earlier study that also found normal cognitive performance in individuals who had been heavy kava users for up to 6 years (Mathews et al, 1988).

The quantities of kava consumed among heavy drinkers in northern Australia are comparable to those in the Pacific islands (Clough et al, 2000). Despite collecting data from among the heaviest reported kava drinkers in the world, no saccadic or cognitive deficits associated with kava use were identified. Moreover, there were no saccadic or cognitive deficits associated with the heavy style of kava use described in the local Gumatj dialect as djadaw'marama. At these recreational doses of kava, the total lactone intake is up to 50 times greater than those taken for the treatment of anxiety and tension (Cairney et al, 2002). This suggests that the therapeutic use of kava products in recommended doses is unlikely to have any adverse effects on the brain. However, recent reports that link hepatotoxicity to the use of these kava products may indicate a need to consider synthesized kava products separately from crude root extractions, as similar incidences have not been reported among individuals who consume a far greater quantity of kava lactones that are derived from the crude root.

Abnormalities of neurological and cognitive function have been observed previously in chronic users of alcohol, cannabis, and petrol (Brust, 1993; Hall and Solowij, 1997; Maruff et al, 1998). However, our test results showed no abnormalities in cognitive or saccade function among chronic kava users. This suggests that long-term kava use did not significantly alter normal brain function, and past or present use of alcohol, cannabis, and petrol did not contribute significantly to any cognitive or saccadic performance in heavy kava drinkers. Thus, our exclusion criteria were appropriate and the consequences of using alcohol, cannabis, and petrol did not confound the results of this study. Similar to patterns of substance use elsewhere in the world, multiple substance use was common among individuals in the community studied. A previous study showed that the combined use of kava and alcohol increased the subjective experience and performance deficits that occurred when alcohol was taken alone (Foo and Lemon, 1997). Despite this evidence, and the greater proportion of alcohol users in the current kava group, we did not detect any cognitive impairments in heavy kava users. However, only irregular and not heavy alcohol users were included in our sample, and it may be necessary to include heavy alcohol users to investigate the effect that combined kava and alcohol abuse has on cognitive function. It may also be necessary to consider the consequences of using kava in combination with other substances, as occurs in this social context, to understand fully any deleterious effects that kava may have on brain function. Such analysis was not possible with the current data and further studies are therefore necessary.

In kava users, the current results show no cognitive indicators of dysfunction that may precede, or lead to the choreoathetotic movements reported among kava users in the literature (Schelosky et al, 1995; Spillane et al, 1997; Clough et al, 2001). This suggests that these involuntary movement reactions occur from acute rather than chronic changes. Another possibility is that the choreoathetosis and psychotic symptoms reported in case studies were not associated with kava at all, or that kava potentiated the effects of other drugs or other neurological or psychiatric disorders to give rise to these disturbances. In summary, despite health consequences such as an increased risk of serious infection, potentially fatal liver damage, and loss of body fat and dermopathy, these data suggest that chronic kava use causes no disruption to human saccade and cognitive processes.

\section{ACKNOWLEDGMENTS}

This study was funded by a grant from the National Health and Medical Research Council of Australia. We gratefully acknowledge the following: Health workers and clinic staff from the community health center, especially Susan Ninikiri Wunungmurra, Djinathi Yunupingu, Rosyln Djarrngana Wunungmurra, Beverley Blakston, Robyn Dixon, and Steven Bryce; Susan Jaccups from Menzies School of Health Research; Michelle Grey and Western Diagnostic Pathology at Darwin Private Hospital and Perth for support with sample collection and processing. Kath Flynn for anthropometric data collection.

\section{REFERENCES}

American Psychiatric Association (1994). Diagnostic and Statistical Manual of Mental Disorders, 4th edn. American Psychiatric Association: Washington, DC.

Baloh RW, Sills AW, Kumley WE, Honrubia V (1975). Quantitative measurement of saccade amplitude, duration and velocity. Neurology 25: 1065-1070.

Becker (1989). Metrics. In: Wurtz RH, Goldberg ME (eds). Reviews of Oculomotor Research: The Neurobiology of Saccadic Eye Movements. Elsevier: Amsterdam.

Blumenthal M (2002). Kava safety questioned due to case reports of liver toxicity. http://www.herbalgram.org/browse.php/ kavaupdate/.

Brunton R (1988). A harmless substance? Anthropological aspects of kava in the South Pacific. In: Prescott J, McCall G (eds). Kava: Use and Abuse in Australia and the South Pacific. (Sydney, National Drug and Alcohol Research Centre Monograph No 5).

Brust JCM (1993). Neurological Aspects of Substance Abuse. Butterworth-Heinemann: Boston.

Burns CB, d'Abbs P, Currie BJ (1995). Patterns of petrol sniffing and other drug use in young men from an Australian Aboriginal community in Arnhem Land, Northern Territory. Drug Alcohol Rev 14: 159-169.

Cairney S, Maruff P, Clough AR (2002). The neurobehavioural effects of kava. Aust NZ J Psychiatry 36: 657-662.

Cairney S, Maruff P, Vance A, Barnett R, Luk E, Currie J (2001). Contextual abnormalities of saccadic inhibition in children with attention-deficit hyperactivity disorder. Exp Brain Res 141: 507-518. 
Cawte J (1986). Parameters of kava used as a challenge to alcohol. Aust NZ J Psychiatry 20: 70-76.

Clough AR, Bailie R, Burns CB, Guyula T, Wunungmurra R, Wanybarrnga SR (2002). Validity and utility of community health workers'estimation of kava use. Aust NZ J Public Health 26: 52-57.

Clough AR, Burns CB, Mununggurr N (2000). Kava in Arnhem Land: a review of consumption and its social correlates. Drug Alcohol Rev 19: 319-328.

Clough AR, Cairney S, Maruff P, Burns CB, Currie BJ (2001). Possible toxicity and withdrawal seizures in Aboriginal kava drinkers in Arnhem Land (Australia). South Pac J Psychol 13: 26-33.

Clough AR, Guyula T, Yunupingu M (in press). Diversity of substance use in east Arnhem Land (Australia): patterns and recent changes. Drug Alcohol Rev.

Collie A, Maruff P, Shafiq-Antonacci R, Smith M, Hallup M, Schofield PR et al (2001). Memory decline in healthy older people: imfplications for identifying mild cognitive impairment. Neurology 56: 1533-1538.

Currie BJ (2000). Infectious diseases of tropical Australia. Med Today 1: 71-81.

Currie J, Joyce S, Maruff P, Ramsden B, McArthur-Jackson C, Malone V (1993). Selective impairment of express saccade generation in patients with schizophrenia. Exp Brain Res 97: 343-348.

Currie J, McArthur C, Ramsden B, Lynch J, Maruff P (1992). Highresolution eye movement recording in the early diagnosis of Huntington's disease. Neuropsychiat Neuropsychol Behav Neurol 5: $46-52$.

Elliot R, Sahakian BJ, Matthews K, Bannerjea A, Rimmer J, Robbins TW (1997). Effects of methylphenidate on spatial working memory and planning in healthy young adults. Psychopharmacology 131: 196-206.

Escher M, Desmeules J, Giostra E, Mentha G (2001). Hepatitis associated with Kava, a herbal remedy for anxiety. $\mathrm{Br} \mathrm{Med} J$ 322: 139.

Foo H, Lemon J (1997). Acute effects of kava, alone or in combination with alcohol, on subjective measures of impairment and intoxication and on cognitive performance. Drug Alcohol Rev 16: 147-155.

Hall W, Solowij N (1997). Long-term cannabis use and mental health. Br J Psychiatry 171: 107-108.

Hall W, Swift W (2000). The THC content of cannabis in Australia: evidence and implications. Aust NZ J Public Health 24: 503-508.

Heinze HJ, Münte TF, Steitz J, Matzke M (1994). Pharmacological effects of oxazepam and kava-extract in a visual search paradigm assessed with event-related potentials. Pharmacopsychiatry 27: 224-230.

Hotson JR, Langston EB, Langston JW (1986). Saccade responses to dopamine in human MPTP-induced parkinsonism. Ann Neurol 20: 456-463.

Lebot V, Merlin M, Lindstrom L (1997). Kava, the Pacific Elixir: The Definitive Guide to its Ethnobotany, History and Chemistry, 2 edn. Healing Arts Press: Rochester, Vermont.

Leigh RJ, Zee DS (1999). The Neurology of Eye Movements, 3rd edn. Oxford University Press: New York.

Maruff P, Burns CB, Tyler P, Currie BJ, Currie J (1998). Neurological and cognitive abnormalities associated with chronic petrol sniffing. Brain 121: 1903-1917.

Maruff P, Tyler P, Burt T, Currie B, Burns C, Currie J (1996). Cognitive deficits in Machado-Joseph Disease. Ann Neurol 40: 421-427.

Mathews JD, Riley MD, Fejo L, Munoz E, Milns NR, Gardner ID et al (1988). Effects of the heavy usage of kava on physical health: summary of a pilot survey in an Aboriginal community. Med J Aust 148: 548-555.

Münte TF, Heinze HJ, Matzke M, Steitz J (1993). Effects of oxazepam and an extract of kava roots (piper methysticum) on event-related potentials in a word recognition task. Neuropsychobiology 27: 46-53.

Owen AM, Roberts AC, Hodges JR, Summers BA, Polkey CE, Robbins TW (1993). Contrasting mechanisms of impaired attentional set-shifting in patients with frontal lobe damage or Parkinson's disease. Brain 116: 1159-1175.

Owen AM, Sahakian BJ, Semple J, Polkey CE, Robbins TW (1995). Visuo-spatial short-term recognition memory and learning after temporal lobe excisions, frontal lobe excisions or amygdalohippocampectomy in man. Neuropsychologia 33: 1-24.

Pantelis C, Barnes TRE, Nelson HE, Tanner S, Weatherly L, Owen AM et al (1997). Frontal-striatal cognitive deficits in patients with chronic schizophrenia. Brain 120: 1823-1843.

Prescott J, Jamieson D, Emdur N, Duffield P (1993). Acute effects of kava on measures of cognitive performance, physiological function and mood. Drug Alcohol Rev 12: 49-58.

Purcell R, Maruff P, Kyrios M, Pantelis C (1998). Neuropsychological deficits in obsessive-compulsive disorder. Arch Gen Psychiatry 55: 415-423.

Robbins TW, Semple J, Kumar R, Truman MI, Shorter J, Ferraro A et al (1997). Effects of scopolamine on delayed-matching-tosample and paired associates tests of visual memory and learning in human subjects: comparison with diazepam and implications for dementia. Psychopharmacology 134: 95-106.

Russell PN, Bakker D, Singh N (1987). The effects of kava on alerting and speed of access of information from long-term memory. Bull Psychon Soc 25: 236-237.

Russmann S, Lauterburg BH, Helbling A (2001). Kava hepatotoxicity. Ann Intern Med 135: 68-69.

Sahakian BJ, Morris RG, Evenden JL, Heald A, Levy R, Philpot M (1988). A comparative study of visuospatial memory and learning in Alzheimer-type dementia and Parkinson's disease. Brain 111: 695-718.

Sahakian BJ, Owen AM, Morant NJ, Eagger SA, Boddington S, Crayton L et al (1993). Further analysis of the cognitive effects of tetrahydroaminoacridine (THA) in Alzheimer's disease: assessment of attentional and mnemonic function using CANTAB. Psychopharmacology 110: 395-401.

Saletu B, Grünberger J, Linzmayer L, Anderer P (1989). EEG-brain mapping, psychometric and psychophysiological studies on central effects of kavain - a kava plant derivative. Hum Psychopharm 4: 169-190.

Schelosky L, Raffauf C, Jendroska K, Poewe W (1995). Kava and dopamine antagonism. J Neurol Neurosurg Psychiatry 58: 639-640.

Singh YN (1992). Kava: an overview. J Ethnopharmacol 37: 13-45. Smit AC, Van Gisbergen JA (1989). A short-latency transition in saccade dynamics during square-wave tracking and its significance for the differentiation of visually-guided and predictive saccades. Exp Brain Res 76: 64-74.

Solowij N, Stephens RS, Roffman RA, Babor T, Kadden R, Miller M et al (2002). Cognitive functioning of long-term heavy cannabis users seeking treatment. J Am Med Assoc 287: 1123-1131.

Spillane PK, Fisher DA, Currie BJ (1997). Neurological manifestations of kava intoxication. Med J Aust 167: 172-173.

Tedeschi G, Bittencourt PR, Smith AT, Richens A (1983a). Specific oculomotor deficits after amylobarbitone. Psychopharmacology 79: 187-189.

Tedeschi G, Bittencourt PR, Smith AT, Richens A (1983b). Effect of amphetamine on saccadic and smooth pursuit eye movements. Psychopharmacology 79: 190-192.

Wang Z, Hoy W, McDonald S (2001). Body mass index in Aboriginal Australians in remote communities. Aust NZ J Public Health 24: 570-575.

Wong AHC, Smith M, Boon HS (1998). Herbal remedies in psychiatric practice. Arch Gen Psychiatry 55: 1033-1044. 